\title{
How inventory consignment programs can improve supply chain performance: a process oriented perspective
}

\author{
Manoj K. Malhotra ${ }^{\mathrm{a}}$, Alan W. Mackelprang ${ }^{\mathrm{b} *}$, Jayanth Jayaram ${ }^{\mathrm{c}}$ \\ ${ }^{a}$ Case Western Reserve University, Cleveland, $\mathrm{OH}$, United States \\ ${ }^{\mathrm{b}}$ Georgia Southern University, Statesboro, GA, United States \\ 'University of South Carolina, Columbia, SC, United States \\ *amackelprang@georgiasouthern.edu
}

\begin{abstract}
Inventory Consignment (IC) has largely been viewed as a method of shifting the ownership and cost burden of inventory from buyer to supplier to benefit the buyer. This primarily accounting based viewpoint has largely ignored process changes that can occur for both the buyer and supplier. This study addresses this gap in the extant literature by examining $1 \mathrm{C}$ from a process perspective by specifically addressing: (1) the implementation issues in an $\mathrm{IC}$ program for both buyers and suppliers and (2) the financial and operational benefits from IC for both buyers and suppliers. Using the case study methodology, we examined three firms that had varying degrees of involvement and roles in $\mathrm{IC}$ programs. Based on our detailed work with these three firms and their supply chain linkages, we offer a series of propositions to demonstrate that $1 \mathrm{C}$ is not just an accounting issue, but also a management practice that requires a series of process changes in order to be successful. These process changes in turn provide operational benefits for both buyers and suppliers via the mechanism of increased demand visibility to suppliers. Through this approach, this study makes a contribution beyond what has been examined in the prior literature which has mostly dealt with $\mathrm{IC}$ as an accounting based inventory management issue.
\end{abstract}

Keywords

Supply chain management. Inventory management. Supplier management. Case studies. Qualitative data analysis.

How to cite this article: Malhotra, M. K., Mackelprang, A. W., \& Jayaram, J. (2017). How inventory consignment programs can improve supply chain performance: a process oriented perspective. Production, 27 , e20170064. http://dx.doi.org/10.1590/0103-6513.006417

\section{Introduction}

Pressures of reducing cost, improving quality, and responsiveness created by global competition has resulted in companies seeking to squeeze inefficiencies such as slow moving inventory out of their supply chains. Thus, there has been an impetus to pursue programs and initiatives that reduce inventory costs. There are many examples of firms utilizing different types of inventory management programs to reduce costs and improve performance. For example, Dell Corporation operates a Just-in-Time (JIT) system to encourage suppliers to tighten inventory controls and ensure that demand is met on a timely basis and customers are satisfied (Kraemer et al., 2000). Additionally, firms such as Campbell Soup, M\&M/Mars, Nestle, Quaker Oats, Nabisco, P\&G, and Scott Paper use Continuous Replenishment (CR) with some of their customers which also result in major inventory reductions (Lee et al., 1997). The adoption of Vendor Managed Inventory (VMI) by Wal-Mart and Procter \& Gamble in the 1980's prompted other leading firms from diverse industries to adopt similar practices. For example, in the high-technology sector, Texas Instruments, Motorola, HP, and Apple use VM1 with some of their suppliers and, in some cases, with their customers as well (Lee et al., 1997). More recently, Novartis (Niranjan et al., 2012), GlaxoSmithKline (Danese, 2004), Boeing and Alcoa (Micheau, 2005), and Nestle and Tesco (Watson, 2005) 
implemented VMI programs, while among others, Chrysler's Mopar parts group implemented Inventory Consignment programs (Douglas, 2008).

Among the above cited inventory management programs, VMI has arguably received the widest attention in the academic literature (Lee et al., 1997; Waller et al., 1999; Wallin et al., 2006; Elvander et al., 2007; Rungtusanatham et al., 2007; Kauremaa et al., 2009; Yu et al., 2012; and Niranjan et al., 2012). While there has been a vast amount of literature devoted to VMl in general (which is summarized in Kauremaa et al., 2009), relatively little attention has been given to another inventory management program referred to as Inventory Consignment (IC) (Pohlen \& Goldsby, 2003; Wang et al., 2012). IC entails ownership of inventory by the seller, even though the stock is physically held at the buyer site. A typical sequence of activities used in IC is detailed in Table 1. Typically, once, the inventory is used in production, ownership then transfers to the buying firm. Unlike traditional VMl programs, inventory ordering still remains the responsibility of the buyer, rather than the seller. Because of the co-mingling of key concepts, $\mathrm{VMl}, \mathrm{IC}$ and traditional inventory management programs are often confused and mistaken for one another. For instance, Dong \& Xu (2002) use VMI and IC as interchangeable terms.

Table 1 . Key steps involved with inventory consignment programs.

\section{KEY STEPS}

1. Buyer/Manufacturer sends forecast to Supplier per appropriate forecast/planning business model.

2. Buyer/Manufacturer issues order release to Supplier per appropriate forecast and planning model.

3. Supplier transfers (ships) goods to consignment warehouse (Buyer's or third party's facility) per shipment model.

4. Inventory is physically located at Buyer's facility (if third party is not used). Buyer/Manufacturer reports usage to trigger transfer of ownership and initiate billing/payment cycle.

5. Ownership transfers from Supplier to Buyer /Manufacturer at Trigger Point, which is specified in contract. Supplier invoices Buyer or payment is triggered electronically per appropriate billing or payment model.

6. Buyer performs inventory counts and reports to Supplier. Supplier may invoice for inventory shrinkage.

7. Supplier is responsible for collection of obsolete goods pick-up and removal from Buyer site.

Additional confusion persists when explicating the difference between inbound and outbound use of inventory management programs. Pohlen \& Goldsby (2003) refer to VMl as a "a coordinated management of finished goods inventories outbound from a manufacturer," but use the term supplier managed inventory (SMI) to refer to the same process when it involves raw materials on the inbound manufacturing side of the supply chain. Holweg et al. (2005) suggest that there are no differences between IC and traditional supply chains when there is no formal collaboration between buyer and supplier. Beyond these discrepancies, there is significant disagreement as to the potential benefits of IC programs. For instance, Pohlen \& Goldsby (2003) postulate that significant benefits can be captured by both firms participating in IC arrangements; but that these benefits are typically not well understood by reluctant supplying firms. Supporting this view, reports from industry suggest significant positive benefits from implementing 1C programs (Sullivan, 2008; and Valentini \& Zavanella 2003). Recently, Xu et al. (2016) found that IC programs can reduce the risk of stockouts, thus benefiting the focal firm. However, Rungtusanatham et al. (2007) found that results obtained from utilizing $1 C$ in a retail setting are far from optimal due to increased information asymmetries and high monitoring costs for retailers.

Using insights gleaned from our case studies in the manufacturing industry, the focus of this paper is to further explicate the costs and benefits of utilizing $\mathrm{IC}$ on the inbound product transformation side of manufacturing, as well as the salient issues both buyers and suppliers should take into account prior to beginning an $\mathrm{IC}$ program. Since we are focusing on the inbound side in this study, henceforth we will use the terms buyers and manufacturers interchangeably. Within that context, this study will address the misconceptions and confusion surrounding IC programs by addressing three primary questions:

(1) What are the primary issues that need to be addressed for both buyers/manufacturers and suppliers when designing and implementing an inventory consignment program?

(2) What process changes are initiated when IC programs are implemented on the inbound side of manufacturing firms?

(3) What are the potential operational and financial benefits for both buyers and suppliers engaged in an inventory consignment program?

Using an exploratory case study methodology, we gathered data from three firms in an effort to evaluate the primary questions motivating this study. Two of the firms (both manufacturers) were seeking to begin an IC program with one another. The buyer had no previous IC experience, while the supplier had significant 
IC experience with some of its other customers. Furthermore, in order to evaluate the benefits of $1 \mathrm{C}$ to a buying firm, we evaluated an additional manufacturer that had experience utilizing $\mathrm{IC}$ as a buyer.

In terms of the organization of this paper, we first describe and compare $1 \mathrm{C}$ to $\mathrm{VMI}$ and traditional inventory practices. We then discuss the differences between an inbound and outbound manufacturing environment as it pertains to inventory management. The methodology and results associated with our case studies is discussed next in detail. Based on the insights obtained through these case studies, we isolate how existing firm processes must change their processes in order to accommodate an IC program. We then provide a detailed discussion of the overarching issues that the firms face with respect to implementing an $\mathrm{IC}$ program, including product, financial, legal, and technical aspects of implementation. Thereafter, the benefits and potential pitfalls of IC programs for both buyer/manufacturer and supplier are discussed, and finally propositions that stem from our findings are presented.

\section{Defining IC, VMI and traditional inventory management programs}

The main points of confusion when trying to explicate the similarities and differences between IC, VMI and traditional inventory management programs typically revolves around three main decisions-- inventory ownership, responsibility for ordering, and the physical location of the inventory. Historically, firms utilized traditional inventory management programs whereby the buyer would determine the ordering parameters and take physical and financial (ownership) control of the inventory. This system has been labeled both a "traditional supply chain" (Holweg et al., 2005) as well as "inventory speculation" (Wallin et al., 2006), and is arguably the most common inventory management system utilized by firms. Traditional inventory management programs differ from inventory consignment on one aspect only - ownership. Whereas in traditional inventory management programs, the ordering, ownership, and physical control of the inventory lies with the buyer, in $1 \mathrm{C}$ programs financial ownership of the component lies with the supplier and shifts to the buyer when the component is actually utilized by the buyer. Finally, VMl programs differ from both traditional inventory management programs and IC programs in that under VMI systems, the responsibility of ordering as well as the ownership resides with the supplying firm, while the physical control of the inventory can be either at the buyer's or supplier's facilities. Under JIT delivery arrangement, which is a type of VMI, the supplier holds the bulk of the inventory at their facilities, but makes frequent deliveries of inventories to the buyers' location based on pre-planned schedules. Therefore, it is possible that under a VMl arrangement, the location of the inventory could be at either the buyer's or supplier's location. Generally speaking, traditional inventory management programs and VMI programs are polar opposites, having little in common, while IC programs are in effect a middle ground with respect to sharing key aspects of both $\mathrm{VMI}$ and traditional management programs. Table 2 illustrates the differences and similarities of the aforementioned inventory management programs with respect to the three main decision points highlighted above.

Table 2. Types of inventory programs.

\begin{tabular}{ccccc} 
& & \multicolumn{3}{c}{ PROGRAMS } \\
\cline { 3 - 5 } & & Traditional Inventory Programs & Inventory Consignment & Vendor Managed Inventory \\
\hline \multirow{2}{*}{ INVENTORY } & Ownership & Buyer & Supplier & Supplier or Buyer \\
DECISIONS & Location of Inventory & Buyer & Buyer & Supplier or Buyer \\
& Ordering Responsibility & Buyer & Buyer & Supplier \\
\hline
\end{tabular}

\section{Methodology}

The underlying purpose of this research is to aid in the theory development process relating to understanding IC programs and their outcomes. Yin (1994) suggests that exploratory case studies can be valuable for determining if further investigation of phenomena is necessary. With this view, three exploratory case studies were conducted to support our research objective of determining the critical issues associated with implementing an $1 \mathrm{C}$ program, as well as any potential risks or benefits resulting from such an implementation for both buyers and suppliers.

Out of the three case study organizations chosen for analysis, two were already in a buyer/supplier relationship, and were exploring entering into an IC program. In this dyadic relationship, the buyer/manufacturer had no previous experience with $\mathrm{IC}$, while the supplier had been in $\mathrm{IC}$ arrangements with several of its other customers. However, in order to gain insights as to the post-implementation risks/benefits from a buyer's perspective, a third case study firm was analyzed because it had significant experience as a buyer in an IC arrangement. 
The data collection in the field was conducted through the participant observer approach (Roy et al., 2011; Maestrini et al. 2016) by the authors because of their involvement with the buying organization (which had no previous $\mathrm{IC}$ experience) in evaluating potential inventory management systems. Schensul et. al. (1999, p. 91) define the participant observation approach as "[...] the process of learning through exposure to or involvement in the day-to-day or routine activities of participants in the researcher setting." As suggested by Spradley (1980), the researchers sought a moderate level of participation so as to strike a balance between being viewed as insiders versus investigators. This level of balance is important in order to observe the interactions of the subjects, but not to influence their decision making or hinder their openness. There are many advantages and disadvantages associated with this data collection method. One of the most significant advantages of this method is the access to greater amounts of higher quality information (DeWalt \& DeWalt, 2002). Specifically, as the subjects became more familiar with the researchers, they also became more forthcoming about their views. However, associated with the potential for higher quality data is the potential limitation of observer and informant induced bias (Johnson \& Sackett, 1998).

Data collection at the selected organizations consisted of utilizing a variety of data collection techniques including obtaining written documentation, utilizing process mapping techniques, and unstructured interviews. The written documentation consisted of production schedules, inventory levels, vendor records, and transportation records. Process mapping procedures were used to organize information obtained from visual observation as well as from written documentation. Furthermore, process mapping helped to facilitate in-depth analysis. Process activity mapping was formally applied to capture the flows of information and material within the plant between the functional areas involved with inventory management and between the focal firm and their suppliers within the supply chain. Utilizing this formal technique, it was possible to identify all of the functions within the firm and outside the firm (their suppliers) that influence the inventory management process and may in turn be influenced by the implementation features of an $1 \mathrm{C}$ program. The unstructured interviews were conducted both on-site and over the phone with purchasing, operations, materials handling and accounting managers over a period of approximately 8 months. Consistent with the method of Butler et al. (2009), we guarded against reliability and validity concerns by interviewing a number of different managers within firms.

\subsection{Single case descriptions}

All firms analyzed have requested anonymity and therefore pseudonyms will be used to identify these firms. In total, data was collected from three firms. Two of these firms were already in a buyer/supplier relationship. However, the buyer, which has no experience with $\mathrm{IC}$, is considering the implementation of an IC program with this strategic supplier, which has significant IC experience with several of its other customers. Furthermore, in order to evaluate the post-implementation risks/benefits to an IC buyer, we have analyzed a third firm with significant IC buying experience. These case descriptions are detailed below.

\subsubsection{Large electronics manufacturer (LEM): no IC experience}

Large Electronics Manufacturer (LEM) is a privately held organization with its headquarters in the USA and employs over 8,000 people worldwide with annual sales of around \$2B U.S. dollars. Our case study location within this firm represents a major U.S. plant located within LEM's worldwide network of plants. The case study plant has approximately 750 employees and accounts for approximately $\$ 255 \mathrm{M}$ in revenue each year. All analysis is limited to this individual manufacturing operation.

LEM is both a supplier of component electronics used in other finished goods, as well as a manufacturer of finished consumer goods. However, the plant in this study manufactures solely finished goods intended for end customer purchase worldwide. Because of the complex nature of the products manufactured at this plant, LEM utilizes roughly 200 vendors that range in size between a few hundred dollars to $\$ 25 \mathrm{M}$ in annual spends. Additionally, there is considerable variation in how much inventory is held on an average for each vendor at LEM. The inventory value per vendor ranges from a few thousand dollars to around \$1.5M. Consequently, the number of inventory turns associated with vendors also has a large range, between 60 turns and 1 turn annually. Because of the large number of vendors and the wide variation of associated annual inventory turns, this LEM site is ideal for evaluating $\mathrm{IC}$ as a potential inventory management system for inbound manufacturing. Currently, LEM utilizes a traditional inventory management system where LEM owns, holds and orders its own raw material inventories. 


\subsubsection{ABC Inc (current supplier to LEM): experienced IC supplier}

$A B C$ Inc is currently a key supplier to LEM. $A B C$ is a wholly owned subsidiary of a major publically held U.S. corporation and employs more than 1,500 employees at locations in North America, Europe and Asia. ABC is the world's largest distributor of passive, connector, electromechanical and discrete components with annual revenues of around $\$ 1 \mathrm{~B}$ dollars. Major product lines include resistors, capacitors, and connectors among others. $\mathrm{ABC}$ has experience in participating in $\mathrm{IC}$ programs as a supplier to some of its other customers. $\mathrm{ABC}$ supplies small components which are stored in bulk at the LEM plant. On an average, the supplied components have lead times typically ranging from 55 to 70 days and safety stock levels ranging between 35,000 units to 400,000 units.

\subsubsection{XYZ-experienced $1 C$ buyer}

$\mathrm{XYZ}$ is a fiberglass weaving firm headquartered in the USA and not associated with either LEM or ABC. XYZ was examined because of their extant success with implementing and utilizing $1 C$. XYZ has been purchasing goods on consignment for several years from a supplier that considers XYZ to be its largest customer.

XYZ produces fiberglass fabrics which are able to withstand high temperatures, while maintaining high dielectric strength and dimensional stability. These types of fabrics are predominantly supplied to the printed circuit industry, and have multiple other applications as well including in the construction industry and in the aviation industry where it goes into aircraft nose cones. Although XYZ has been in business for nearly 100 years, it wasn't until the 1980's that XYZ began to focus on its glass weaving operations. In conjunction with its other weaving operations, XYZ serves customers worldwide and produces annual revenues of approximately $\$ 200 \mathrm{M}$ dollars with about 900 employees.

\section{Case study findings: IC process considerations}

The first research question addresses issues that firms should consider prior to entering into an IC agreement. While it is commonly believed that IC programs only involve moving the point at which ownership of inventory changes hands, we learned through evaluation of our case study firms that IC programs become effective through changing existing processes. By analyzing the written and verbal information provided by LEM and ABC, we have identified four specific processes that would be most significantly influenced in an IC implementation. The following subsections detail how these processes, which are denoted and shown in Figure 1, are changed by the implementation of an IC program. Subsequently, in line with the case studies of Oke \& Gopalakrishnan (2009), Tate et al. (2009) and Tzeng et al. (2008), we provide propositions based on our case study findings.

\subsection{Production planning and information sharing}

Many of the benefits that result from an IC program for a supplier are derived from improved production planning and information sharing processes. As detailed in Table 3, LEM currently utilizes production planning and information sharing processes that are commonly used among large electronic manufacturers. LEM electronically sends $A B C$ their MRP schedule monthly in addition to providing weekly and monthly demand figures. While this process of coordinating production requirements provides $A B C$ with some insight into LEM's future demand, the transmission of information is not frequent enough to provide $A B C$ accurate insights into the real-time rate of consumption of its supplied components. Under an IC program, the current process can be improved as the software required to track the change in inventory ownership of the $\mathrm{IC}$ components can also facilitate sharing real-time usage data with $A B C$ via the internet. This process change is relatively minor for the buyer or the manufacturer, but has the potential to significantly improve the information sharing process between buyer and supplier as well as the demand visibility for the supplier.

\subsection{Materials handling: inventory placement}

LEM uses an ERP system to facilitate all inventory related activities. As detailed in Table 3, when LEM receives a shipment from $A B C$, it matches the parts against outstanding purchase orders and then the part information is manually inputted into the ERP system. Under an IC program, this current process is amended such that when parts are received at LEM, they must first be determined either to be consigned or non-consigned. The ERP system therefore must be updated to include a new field for this designation. Much of the success of an IC program 


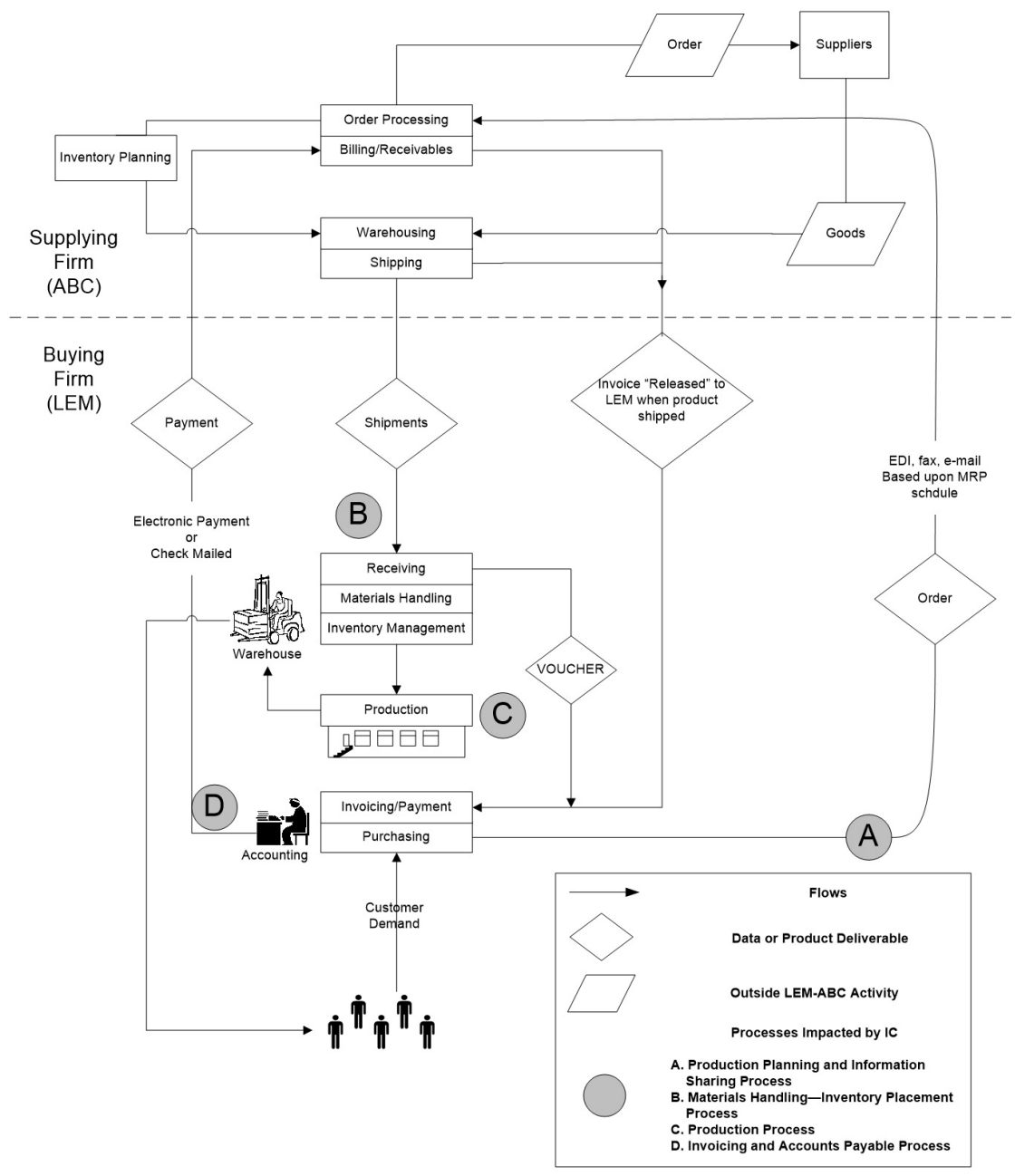

Figure 1. Pre-inventory consignment order processing and product flow diagram.

Table 3. Processes impacted by inventory consignment.

\begin{tabular}{|c|c|c|c|}
\hline Process & Area of Focus & Current Procedure & Potential process changes resulting from IC \\
\hline $\begin{array}{l}\text { A. Production Planning } \\
\text { and Information Sharing }\end{array}$ & $\begin{array}{l}\text { Coordination of } \\
\text { production requirements } \\
\text { and scheduling between } \\
\text { LEM and } A B C\end{array}$ & $\begin{array}{l}A B C \text { receives LEM's MRP schedule } \\
\text { monthly } \\
\text { LEM emails monthly and weekly demand } \\
\text { schedule to } A B C\end{array}$ & $\begin{array}{l}\text { Make real-time production usage available } \\
\text { online for } A B C\end{array}$ \\
\hline \multirow{2}{*}{$\begin{array}{l}\text { B. Materials Handling-- } \\
\text { Inventory Placement }\end{array}$} & $\begin{array}{l}\text { Data Entry for Specific } \\
\text { Components }\end{array}$ & $\begin{array}{l}\text { After parts are matched against purchase } \\
\text { order (PO), the part information is } \\
\text { manually entered into the ERP system }\end{array}$ & $\begin{array}{l}\text { When parts are received, they are designated } \\
\text { "CONSIGNMENT" or "NON-CONSIGNMENT" } \\
\text { ERP system must be amended to include } \\
\text { CONSIGNMENT designation for parts }\end{array}$ \\
\hline & $\begin{array}{l}\text { Physical Placement of } \\
\text { Inventory }\end{array}$ & $\begin{array}{l}\text { After parts have been entered into } \\
\text { the ERP system, they are shelved in } \\
\text { designated locations }\end{array}$ & $\begin{array}{l}\text { Consigned inventory is located separately from } \\
\text { non-consigned inventory }\end{array}$ \\
\hline C. Production & Backflush Process & $\begin{array}{l}\text { After a period of production, the } \\
\text { backflush updates the ERP system to } \\
\text { reflect changes in inventory levels due to } \\
\text { production }\end{array}$ & $\begin{array}{l}\text { Backflush becomes trigger point where } \\
\text { ownership transfers from ABC to LEM } \\
\text { Daily backflush triggers the creation of } \\
\text { a voucher which is used to formalize the } \\
\text { inventory ownership transfer }\end{array}$ \\
\hline $\begin{array}{l}\text { D. Invoicing and } \\
\text { Accounts Payable }\end{array}$ & $\begin{array}{l}\text { Matching Vouchers against } \\
\text { Purchase Orders (PO) }\end{array}$ & $\begin{array}{l}\text { Invoices received by LEM are matched } \\
\text { against ERP system PO records and then } \\
\text { paid }\end{array}$ & $\begin{array}{l}\text { LEM sends vouchers to } A B C \text { daily reflecting } \\
\text { the quantity of } A B C \text { components consumed in } \\
\text { production in that period. } \\
\text { Based on the } 1 C \text { contract terms, LEM pays } \\
A B C \text { for the quantity of components used by } \\
\text { LEM in production. }\end{array}$ \\
\hline
\end{tabular}


hinges on the buyer being able to track its consigned parts accurately (Rungtusanatham et al., 2007); otherwise many of the potential benefits of $\mathrm{IC}$ for both buyer and supplier will go unrealized.

Furthermore, under LEM's current process, after parts are entered into the ERP system, they are shelved in their designated area. Under an IC program, the consigned inventory must be tracked; LEM prefers to facilitate easier tracking through physically separating consigned inventory from non-consigned inventory. As the consigned inventory is utilized in production, LEM, through utilizing their ERP system, is able to provide $A B C$ a periodic "aging schedule" which details the age of its consigned inventory. This report, in conjunction with the real-time production visibility can allow $A B C$ to identify how much of its consigned inventory is becoming "slow moving" or obsolete, as well as also aid LEM in adjusting its ordering quantities from ABC.

\subsection{Production}

As identified in Table 3, the current production backflush process at LEM is utilized to "remove" inventory from their ERP system after the inventory has been consumed in production. Under an IC agreement, the production backflush is commonly the trigger point where ownership of the consigned inventory passes from the supplier to the buyer, or in this case potentially from ABC to LEM. When the parts are backflushed, the ERP system will reflect that the consigned part has been used in production and will be included on the next accounts payable voucher for $A B C$. The voucher for $A B C$ is the mechanism that notifies LEM's accounts department the quantity of ABC's materials that were utilized in production during the period, and subsequently can be used to determine how much to pay $\mathrm{ABC}$.

\subsection{Invoicing and accounts payable}

The invoicing and accounts payable processes are arguably most significantly impacted by an IC program. Currently, LEM's suppliers will mail or electronically transmit an invoice to LEM, after which the invoice is matched against the ERP purchase order information and ultimately paid (See Table 3). Under an IC arrangement, LEM would not need to pay their suppliers until the supplied parts were used in production. The backflush process detailed earlier starts the LEM accounts payable process for consigned goods. Once production is backflushed and the consigned parts have been utilized in production, the ERP system is updated to reflect the quantity of consigned parts utilized in production during the period. Daily or as often at the $1 C$ contract specifies, a voucher is generated showing the quantity of consigned parts used during the period. These vouchers, which show that the parts have been used, are then sent to both $A B C$ and LEM's accounts payable department. LEM will then pay $\mathrm{ABC}$ for the vouchered items based on the terms outlined in their IC contract.

Based upon the above findings we posit the following:

Proposition 1: An inventory consignment program between buyer and supplier impacts (1) production planning and information sharing process by tapping into common databases or software program features, (2) materials handling process through an updating of a data field to differentiate consigned parts from non-consigned parts, (3) production process via integration with the ERP back flush process and (4) invoicing and accounts payable process by integrating with the ERP back flush process to signal timing of payments to suppliers.

\section{Case study findings: overarching ic considerations}

In addition to the process considerations outlined above, firms must also consider overarching issues that don't necessarily impact just a single process, but can impact the overall effectiveness of an 1C program. These overarching considerations should be addressed when considering entering into an $1 \mathrm{C}$ program. We detail product, financial, legal and technical overarching considerations in the following subsections.

\subsection{Pre-1C implementation-product considerations}

An important decision in implementing an $\mathrm{IC}$ program is determining which products to consign. The product components for a printed circuit board for a PC assembler such as Dell are quite different than the components for an auto manufacturer such as Toyota. These differences manifest themselves not only in product value, but also in physical dimensions, quality standards, and number of raw materials needed for the finished product. Likewise, even within a single firm like LEM, there are a wide range of sourced components with differing 
degrees of compatibility with an IC program. It is important to evaluate the following two criteria in particular when choosing which components, products, or family of products to consign.

\subsubsection{Product value}

Product value is commonly calculated by multiplying the product cost with the product throughput (the product's volume, typically on a monthly basis). Thus, greater frequency of usage as well as higher actual component cost equates to higher value. Products that are expensive, and which continually move on-and-off the shelves, are better candidates for consignment from the buyer's perspective. XYZ confirms that the frequency/movement of the product is critical if it is to be consigned. XYZ consigns inventory primarily based on the most recent demand trends of its key customers. That way the company is able to better manage its own production processes and delivery schedules to meet the changing demands of its customers, who frown upon stock-outs, particularly for the fast moving, high demand products (personal communication with managers at XYZ). Additionally, buyers are able to free-up more capital through consignment with high value products relative to low value products.

\subsubsection{Physical size of product (product size)}

Product Size is commonly measured as the actual physical space one unit of product occupies. There is subjectivity with this measurement, since not all components are accurately measured for their volume due to non-symmetrical packaging or unit features. We have seen measurements ranging from squared to cubic volume-based metrics. All things equal, the bigger the product is, the less desirable it is for consignment. Keeping excess supply of bulky, slow moving items in a warehouse can take up needed space for core fast moving components. Larger items on the other hand are especially good candidates for VMl, where the supplier holds the inventory at their location until the buyer needs it.

\subsection{Pre-1C implementation-financial considerations}

The financial linkage between the buyer and supplier is arguably the most important consideration when determining whether or not to enter into an $\mathrm{IC}$ program. Figure 1 illustrates the significant financial process ties between buying and supplying firms. Central to the inter-firm financial intersections is both the cost of physically holding inventory and the cost of owning the inventory. Under the proposed $\mathrm{IC}$ scenario with $\mathrm{ABC}$ and LEM, $A B C$ would retain ownership of the inventory until it passes through the Trigger Point, which is the point at which LEM uses the inventory in production and ownership shifts from ABC to LEM. The inventory value on LEM's Balance Sheet would reflect only the value of inventory that has been used in production beyond the Trigger Point. Therefore, the predominant financial implications of an $\mathrm{IC}$ program are inventory carrying costs and the cost of capital. These specific financial considerations are detailed below.

\subsubsection{Carrying costs}

Under an IC arrangement, it is possible that either the buyer or the supplier could physically hold the consigned inventory. Therefore, inventory carrying costs consisting of inventory management and material handling expenses for the holder of the consigned inventory become relevant costs for both $\mathrm{IC}$ parties. $\mathrm{ABC}$ believes that the party that holds the consigned inventory, could in fact incur higher inventory carrying costs due to the potential of increased manual processes related to managing consigned goods, increased cycle counting, higher insurance costs, increased material handling requirements, tighter controls, and higher security measures. However, under IC it is possible that the partnering firms may agree to jointly invest in IT systems that automate much of the tracking and administration of the consigned parts. While initially costly, automation of the $\mathrm{IC}$ program through IT systems could potentially lower inventory carrying costs by eliminating labor intensive steps and the associated costs, thus justifying return on the initial cost of the IT investment. Typically, inventory carrying costs for the holder of the consigned inventory in $1 C$ environments are equal to or less than those seen in traditional inventory management environments.

Before entering into an $\mathrm{IC}$ arrangement, both parties should have a good idea of the inventory carrying costs of whichever partner is to hold the consigned inventory within the IC program. Generally, firms that hold the inventory will try to include some or all of these costs in the IC pricing scheme. Therefore less costly $\mathrm{IC}$ programs often have consigned inventory held by the partner with the lower inventory carrying costs. Overall, inventory 
carrying costs will have an impact on not only which $\mathrm{IC}$ partner holds the consigned inventory, but also which buyers/suppliers are even potential IC partners.

\subsubsection{Cost of capital}

For the buyer, inventory purchases are no longer paid in advance; rather they are invoiced with the billing period initiated at the Trigger Point. The Trigger Point and the Billing Terms are nearly always specifically spelled out and defined in the contractual agreement between the buyer and supplier. Therefore, the timing of payment is critical and represents an opportunity cost for the supplier and an investment opportunity for the buyer. The true annual financial benefit to the buyer can be represented by the product of the additional annual cash flow generated by only owning the consigned inventory after it passes through the Trigger point multiplied by one plus the weighted average cost of capital (WACC). Because most firms' capital sources are derived from either bond or equity markets, the WACC is calculated by determining the weighted cost of borrowed funds and represents, for most firms, the breakeven rate of return for internal projects. Similarly, if a firm has other potential investment opportunities, the firm's minimum acceptable rate of return or "hurdle rate" can be used to calculate the financial benefit of not owning the inventory that is part of an $\mathrm{IC}$ arrangement.

An increase in WACC, or the cost of borrowed funds, represents the potential savings for the buyer by transferring the cost of inventory from buyer's balance sheet to supplier's balance sheet. In-turn these savings can then be utilized or invested in other opportunities that generate additional revenues. Therefore, the total financial benefits the company can expect to achieve through $\mathrm{IC}$ is not limited to merely savings related to not owning inventory, but also to the additional returns generated by those savings.

Conversely, since the supplier will own the consigned inventory until it passes through the Trigger point at which time the buyer will assume ownership, the supplier will generally need to own more inventory than they otherwise would under a traditional inventory agreement. This additionally owned inventory will tie up additional capital that could have otherwise been utilized within the supplier firm. Suppliers that have a high cost of capital may be less inclined to enter into an IC agreement because of the extra capital costs involved. Likewise, buyers with low capital costs and low opportunity costs may also be inclined to avoid an IC agreement. However, the opposite is also true, when capital costs of the supplier are low and the capital costs of the buyer are high; both are incentivized to enter into an IC relationship.

Both the buyers and suppliers cost of capital should simultaneously be taken into account before firms enter into an IC relationship. Without sufficient understanding of these implications, firms may not see the intended benefits of an IC program and even see reduced financial performance. Furthermore, in many cases, both buyer and supplier can benefit from cost reductions associated with increased supply and demand visibility. However, unlike cost of capital and inventory holding costs, the implications of improved supply and demand visibility are largely unknown prior to an IC implementation.

\subsubsection{Government regulation}

IC programs in the U.S. are subject to increased scrutiny since the passing of the Sarbanes-0xley Act (SOX) of 2002. In complying with section 401 of SOX, all "off-balance sheet" transactions are required to be reported. All supplier-owned inventory programs are considered "off balance sheet" arrangements. As such there could be considerable cost in reporting such transactions (Craig, 2006). Furthermore, supplier owned inventories could fall under the "outsourcing" clause found in section 404. If this is the case, then the supplier would have to demonstrate and document sufficient internal controls and safeguards (Craig, 2006). The regulatory pressure, coupled with the fuzziness of SOX guidelines, have made many firms leery of entering into new programs or staying with existing inventory management programs such as IC (Ashenbaum, 2006).

\subsection{Pre-1C implementation technical considerations}

The technical implications associated with an $\mathrm{IC}$ implementation are primarily driven by the size and scope of the IC program. IC programs require specific tracking of inventory, primarily for accounting purposes. Both buyers and suppliers desire accurate records of which inventory has indeed passed through the Trigger point where ownership shifts from the supplier to the buyer. In the case between $A B C$ and LEM the size and scope of the potential IC program being considered is relatively small. So any technical/IT considerations are manageable in scope. However, if LEM were to enter into an IC relationship with all of its largest suppliers, then the technical considerations would become a significant issue. For example, Chrysler's Mopar parts group utilizes 
IC with 3,000 suppliers and 280,000 parts located globally (Douglas, 2008). The magnitude of this IC program could not be successfully accommodated with a manual process. Instead Mopar utilizes specialized web-based software that allows all parties real-time access and visibility to their consigned inventory. Additionally, the system that Mopar utilizes requires supplier participation, whereby on a weekly basis Mopar and their suppliers compare inventory counts and any discrepancies are corrected expediently. Although the cost of such systems decline over time, smaller suppliers may find the initial capital costs of developing an IT infrastructure formidable.

IC programs that do not need or match Mopar's robustness may be more inclined to utilize a manual IC process. However, many of the visibility benefits (discussed in detail in later sections) for the supplier become more difficult to obtain with manual processes because of the time lag involved in reporting inventory levels. Additionally, overall costs may rise because of the potential inaccuracy of inventory records. Generally, under these conditions, the supplier would be more damaged than the buyer, because the payment for inventory used may take place well after the item has already passed through the Trigger point. Overall, both buyer and supplier should examine and understand the technical requirements involved with an IC program prior to making an agreement.

Because of the monetary and information related investments associated with many $1 \mathrm{C}$ technical requirements (such as that with Mopar's IC system), both buyers and suppliers are subject to increasing asset specificity which can lead to a "lock-in" situation, whereby both parties must continue the relationship or forfeit the asset specific investments (Waller et al., 1999). Furthermore, depending on the degree of mutual dependence within the relationship, the level of asset specificity involved with meeting the technical requirements may lead to opportunism in the relationship. Therefore, prior to entering into an $\mathrm{IC}$ relationship, both parties should fully understand the required technical investments and evaluate these investments against the potential benefits of an IC partnership.

\subsection{Pre-1C implementation-legal considerations}

Because an IC program involves both a buyer and seller and is inherently contractual in nature, there are important legal implications for both parties. The importance of crafting a winning scenario for both parties cannot be overemphasized. The number one priority is to put a structure in place which enables each partner to generate their desired beneficial outcomes. The major legal considerations predominantly center on the degree of flexibility and negotiability of the contract. Each of the following legal aspects requires consideration prior to entering into an $\mathrm{IC}$ agreement.

\subsubsection{Flexibility}

One particular area of flexibility is the length of the IC contract. LEM in general expects its suppliers to reduce product cost by 5\% to 10\% year-over-year. Thus, if committing to an $1 \mathrm{C}$ program, the company would like to ensure that such a cost advantage is not lost over the long-term. For low margin, cost reducing product segments, the buyer's desirability to consign is less; unless there is a stipulated clause for re-negotiation of prices on a continual basis. Therefore, both buyer and supplier should select the proper timeframe of an IC agreement such that both parties are satisfied with the re-negotiation period. The extent of initial investment also plays a role in selecting an appropriate timeframe. Large initial investments will require longer contracts in order to recoup the initial capital outlays. Likewise, the clockspeed of the industry will also play a role in determining a proper IC contract timeframe. Industries with faster clock speeds should generally have shorter IC contracts than those in slow clockspeed industries.

\subsubsection{Negotiability}

With regards to negotiability, bullying a supplier will not create long-term benefits for a buyer/manufacturer. Nor will it increase system-wide service levels or reduce system-wide costs. A supplier needs continuous motivation to increase inventory efficiency and find ways to lower costs. All relevant details must be covered. For instance during negotiations, it is important to determine which party will monitor inventory turnover and how slow moving or obsolete goods will be handled; whether these items will be returned to the supplier or sold off by the buyer at discounted values. Traditionally, the onus has been on the buyer, but can shift to the supplier in many cases. The buyer also seeks motivation for continuous improvements. Negotiating to find this balance is essential; performing to meet mutual expectations is vital. Thus, establishing a sound IC contract begins the foundation on the basis of which this goal can be accomplished. 


\subsubsection{The contract}

Based on our case study findings and discussions with managers in other firms, we isolated several salient contractual issues that must be explicitly considered before entering into an inventory consignment decision. These issues are described in Table 4, where it is also noted whose interest is best served by that contractual issue. Some issues impact only the buyer or the seller, while others reach across both parties. Depending upon the nature of relationship between the buyer and the seller, it may be valuable for both parties to enter into legally binding contracts covering the issues detailed in Table 4 before commencing an IC program.

Table 4. Key contractual issues to be considered before a consignment decision is made.

\begin{tabular}{lcc}
\hline \multicolumn{1}{c}{ Issue } & Buyer Interest & Supplier Interest \\
\hline When does transfer of ownership occur (setting the Trigger Point)? & $\mathrm{X}$ & $\mathrm{X}$ \\
Establishing length of contract & $\mathrm{X}$ & $\mathrm{X}$ \\
Setting a cut-off point when buyer is obligated for goods (regardless of sale) & $\mathrm{X}$ & $\mathrm{X}$ \\
Determining date of obsolescence for consigned product & & $\mathrm{X}$ \\
Setting Accounts Payable period & $\mathrm{X}$ & $\mathrm{X}$ \\
Setting Bill lnvoicing dates (i.e. check runs, EDl transfers) & $\mathrm{X}$ & $\mathrm{X}$ \\
Establishing control and security for product (who assumes responsibility?) & & $\mathrm{X}$ \\
Defining tasks for each party (i.e. cycle counts, material and storage, etc.) & \\
lnsuring the consigned products & & $\mathrm{X}$ \\
Determining set levels of product volumes/sales (if applicable) & & \\
\hline
\end{tabular}

Based upon the above findings we posit the following:

Proposition 2: Successful inventory consignment programs between buyer and supplier are more likely to occur when (1) product issues like physical size, (2) financial issues like cost of capital for supplier and buying firms, (3) technical issues such as tracking capabilities through electronic means and (4) legal issues such as length of contract, negotiating styles and details of the contract; have been considered prior to inventory consignment implementation.

\section{Case study findings-1C benefits}

In order to understand the potential benefits of $\mathrm{IC}$ for buyers and suppliers, we have analyzed $\mathrm{ABC}$, a firm that has significant experience with IC from a supplier's perspective, XYZ a firm with significant experience utilizing $\mathrm{IC}$ as a buyer, and LEM, which has no experience with $\mathrm{IC}$, but is examining implementing it with its supplier ABC. The potential implementation benefits are detailed subsequently for both buyers and suppliers in an $1 C$ arrangement.

\subsection{Buyer financial benefits of $1 C$}

The most direct financial benefit of $\mathrm{IC}$ for the buyer is the savings associated with supplier retaining ownership of the inventory until the buyer utilizes it in their production. For example, over a span of two years, $\mathrm{XYZ}$, the case study firm that has extensive $\mathrm{IC}$ experience as a buyer, reduced the amount of inventory carried on its Balance Sheet from $\$ 1.6$ million to $\$ 400,000$ (Personal communication with manager at XYZ). Likewise, it is projected that LEM at the single manufacturing facility evaluated in this study could free $\$ 1.7 \mathrm{M}$ in capital by simply implementing an IC program with its top 4 semiconductor suppliers. An expanded IC program with LEM's 20 largest suppliers could free up $\$ 10 \mathrm{M}$ in capital. Furthermore, depending on the various rates of return possible, LEM could invest this freed-up capital into research and development and other higher yielding activities.

\subsection{Buyer manufacturing benefits of $\mathrm{IC}$}

There are several common manufacturing benefits that IC programs elicit. IC achieves fewer stock-outs and raw material shortages while preserving the freshness of inventory through reducing the amount of inventory in the system. The 75\% reduction in XYZ's inventory levels due to their IC program has allowed the company to better mesh its eight-week production lead-time with a less than one-day delivery lead-time to its downstream 
customers in the printed circuit board industry. Although under the IC program only the ownership of the inventory shifted between $\mathrm{XYZ}$ and their supplier, the $\mathrm{IC}$ mechanisms put in place to monitor the transfer of inventory ownership resulted in $\mathrm{XYZ}$ monitoring their inventory much more closely and in-turn improved their inventory and manufacturing performance. Furthermore, $\mathrm{ABC}$ also saw its customer's inventory turns commonly increase from 12 to 20 times per year through the implementation of an IC program. These improvements in inventory performance are generally a result of improved inventory tracking, control, handling and security.

\subsection{Supplier benefits of $1 C$}

A common misnomer relating to IC programs is that suppliers receive no increased demand visibility. Holweg et al. (2005) state that inventory consignment "is not simply another term for vendor managed inventory as many managers wanted to make us believe." Furthermore, Holweg et al. (2005) posit that IC cannot produce the same dynamic results as VMI because "the change in the ownership of the inventory does not change how the replenishment orders are generated: the same decisions are being made, based on the same information as in a traditional supply chain, and thus no dynamic benefit is derived." However, this view does not take into account modern information technology systems that are required for sophisticated IC programs. First generation IC programs provided little insight to the suppliers with respect to the buyers' demand patterns. However, because of the scope and complexity of most modern IC systems, IT systems are required to keep track of the ownership of the inventory. Managers at $\mathrm{ABC}$, which has customers that use both traditional inventory and $1 \mathrm{C}$ programs, suggest that their demand visibility is much better with their IC customers than with their traditional inventory customers. Because of the size and complexity of most IC programs, accounting departments demand sophisticated software to keep track of "trigger points" where ownership passes from supplier to buyer. These systems in effect act as a collaboration mechanism between firms. Supplying firms are able to monitor in real-time the pace of inventory transfer, which is in effect the rate of actual demand usage. This real-time information therefore can provide many of the same visibility benefits to suppliers as those found with VMI programs.

Based upon the above findings we posit the following:

Proposition 3: Inventory consignment programs when implemented successfully, can improve performance for both the buyer (through reduction in inventory and other related working capital needs) and the supplier (through an increase in value added services for a variety of customers, primarily through better demand visibility and planning capabilities).

\section{Case study findings-post-1C implementation problems}

Inventory Consignment programs have risks and can create problems for partner firms. A common potential problem with ongoing $\mathrm{IC}$ programs is the risk of increasing asset specificity by the supplier to a few or single customers. Asset specificity might take a form of capital investments such as dedicated processes or technology for customized IT systems invested by the seller to synchronize with the buyer's IT systems (Waller et al., 1999). Suppliers become "locked into" a relationship which may be hard to get out of because of the potential to increase their share of their customer's business. Buyers may increase their suppliers business incrementally as to gradually lock in IC suppliers. As suppliers get "locked-in" via increased asset specificity, buyers may become increasingly opportunistic throughout the IC relationship. However, the supplier/vendor might simply decide that the cost of serving the buyer through the $\mathrm{IC}$ arrangement exceeds the revenue generated from a risky single (or dominant) customer business. The supplier must be careful that the buyer has a long-term vision in place. Thus, the supplier often has an important decision to make - either decline the requests related to "lock-in" situations and risk the possibility of losing key business, or make the concessions and soak up incremental costs in hopes of greater sales orders. According to the managers at $A B C$ lnc, one of the firms we studied, the only defensive measure a supplier can take is to increase the service cost of the program. This can cover the opportunity cost of the program from the supplier's side, but may also deter the buyer from requesting future business.

Based upon the above findings we posit the following:

Proposition 4: As asset specificity increases within an inventory consignment agreement, the benefits of the inventory consignment program may be reduced for either the buyer (as the supplier is able to deflect this dependence by pursuing other customers or the supplier (by the buyer preserving the lock-in situation and its ensuing threat of limited assured business to the locked in suppliers). 


\section{Conclusions}

We have illustrated how and why inventory consignment programs can be effective supply chain initiatives. Depending on the impetus of the parties involved, the result of a successfully implemented program is a 'win win' for both buyers and suppliers. System-wide savings and information transparency can be achieved. Furthermore, we demonstrated that if software is used to track the $\mathrm{IC}$ program, IC programs can provide the same dynamic inventory visibility benefits as evidenced in VMl programs. However, there are also significant problems for both buyers and suppliers that can arise from entering into an IC arrangement with an inappropriate partner. For instance, both buyers and suppliers may make significant investments in specific assets, such as IT systems or employee training, that are not easily applied to other sourcing contexts. This increased asset specificity in a sense "locks in" the agreement and results in higher switching costs for both buyer and supplier. The associated benefits and problems for both buyers and suppliers are summarized in Table 5.

Table 5. Potential benefits and problems for suppliers and buyers participating in $1 \mathrm{C}$ programs.

\begin{tabular}{|c|c|c|c|}
\hline & & SUPPLIER & BUYER/MANUFACTURER \\
\hline \multirow{6}{*}{$\begin{array}{l}\text { POTENTIAL } \\
\text { BENEFITS }\end{array}$} & \multirow{3}{*}{$\begin{array}{l}\text { Inventory } \\
\text { Related }\end{array}$} & $\begin{array}{c}\text { Reduced warehousing costs if inventory is held at the } \\
\text { buyer's location }\end{array}$ & Reduced inventory costs (cost of capital) \\
\hline & & Increased demand visibility & Greater visibility of inventory \\
\hline & & & Increased inventory turns \\
\hline & \multirow{3}{*}{ Other } & Increased business and revenues & Increased production velocity \\
\hline & & Closer proximity to customer & Reduced stock outs \\
\hline & & & Strengthened supplier relationships \\
\hline \multirow{7}{*}{$\begin{array}{l}\text { POTENTIAL } \\
\text { PROBLEMS }\end{array}$} & \multirow{4}{*}{ General } & \multicolumn{2}{|c|}{ Mismatched goals } \\
\hline & & \multicolumn{2}{|c|}{ Misaligned objectives } \\
\hline & & \multicolumn{2}{|c|}{ Non system wide thinking } \\
\hline & & \multicolumn{2}{|c|}{ IT system that tracks when inventory changes ownership } \\
\hline & \multirow{3}{*}{ Specific } & Increased capital tied up in inventory & $\begin{array}{l}\text { Increased accounting costs i.e. Sarbanes-0xley } \\
\text { reporting }\end{array}$ \\
\hline & & \multirow[t]{2}{*}{ Increased asset specificity i.e. forced consignment } & Increased switching costs \\
\hline & & & $\begin{array}{c}\text { Increased cycle-counting and security required by } \\
\text { Supplier }\end{array}$ \\
\hline
\end{tabular}

Inventory Consignment programs hold their own with other forms of inventory management programs if the business case is truly well defined and the resulting 'outcomes' -- both in dollars and efficiencies -- are shared among both parties involved. It can be a source of competitive advantage under the right set of conditions and circumstances as outlined in this paper, and a stepping stone to enhanced logistics and supply chain performance.

While the primary purpose of this research was to address a gap in extant literature related to inbound manufacturing inventory management programs, the recommendations presented here through multiple case studies also benefits practitioners grappling with these issues. The insights and frameworks contained in this research thus contribute both to practice as well as the theoretical development of the inventory management literature in the field.

\subsection{Directions for future research}

Due to the qualitative nature of this research study, a number of avenues for further research are identified. First, our insights are based upon our experience with the involved firms, however, we encourage further research into the generalizability of both the potential benefits and potential problems of $1 \mathrm{C}$ programs. Aspects of generalizability could include country effects (e.g. Brazil, China, India etc.), firm size (buyer, supplier), product type (consumer vs industrial) and industry (manufacturing vs retail). Additionally, future research could provide more specific estimates as to the magnitude of any benefits and/or problems. Are there potential benefits and/or problems that have a dominating effect and should be examined further? Additionally, what are the characteristics of firms that predominantly benefit vs those that typically have IC related problems? In summary, we see ample opportunities for future research related to IC programs and encourage continued development into this important research area. 


\section{References}

Alpert, B. (2003, November 10). On the Ball: IBM finds its balance: just as businesses may boost tech spending (pp. 26). Barron's.

Ashenbaum, B. (2006). Optimizing MRO inventory management. Arizona: CAPS Research. Critical lssues Report. Retrieved in 30 October 2006, from http://www.capsresearch.org/Publications/pdfs-protected/cir082005.pdf

Butler, M. J., Sweeney, M., \& Crundwell, D. (2009). Facility closure management: the case of Vauxhall Motors Luton. International Journal of Operations \& Production Management, 29(7), 670-691. http://dx.doi.org/10.1108/01443570910971379.

Craig, T. (2006). Sarbanes-oxley and supply chain management. WebProNews. Retrieved in 30 October 2006, from www.webpronews. com/enterprise/crmanderp/wpn-15-20050512SarbanesOxleyandSupplyChainManagement.html

Danese, P. (2004). 'Beyond vendor managed inventory: the glaxosmithkline case,' supply chain forum. International Journal, 5(2), 32-39.

DeWalt, K. M., \& DeWalt, B. R. (2002). Participant observation: a guide for fieldworkers. Walnut Creek: AltaMira Press.

Dong, Y., \& Xu, K. (2002). A supply chain model of vendor managed inventory. Transportation Research Part E, Logistics and Transportation Review, 38(2), 75-95. http://dx.doi.org/10.1016/S1366-5545(01)00014-X.

Douglas, M. (2008). You may have it, but we can see it. LIT Toolkit. Retrieved in 28 October 2006, from http://www.inboundlogistics. com/articles/toolkit/toolkit1104.shtml

Elvander, M. S., Sarpola, S., \& Mattsson, S.-A. (2007). Framework for characterizing VMl Systems. International Journal of Physical Distribution \& Logistics Management, 37(10), 782-798. http://dx.doi.org/10.1108/09600030710848914.

Holweg, M., Disney, S., Holmström, J., \& Småros, J. (2005). Supply chain collaboration: making sense of the strategy continuum. European Management Journal, 23(2), 170-181. http://dx.doi.org/10.1016/j.emj.2005.02.008.

Johnson, A., \& Sackett, R. (1998). Direct systematic observation of behavior. In H. R. Bernard (Ed.), Handbook of methods in cultural anthropology (pp. 301-332). Walnut Creek: AltaMira Press.

Kauremaa, J., Småros, J., \& Holmström, J. (2009). Patterns of vendor-managed inventory: findings from a multiple-case study. International Journal of Operations \& Production Management, 29(11), 1109-1139. http://dx.doi.org/10.1108/01443570911000159.

Kraemer, K. L., Dedrick, J., \& Yamashiro, S. (2000). Refining and extending the business model with information technology: dell computer corporation. The Information Society, 16(1), 5-21. http://dx.doi.org/10.1080/019722400128293.

Lee, H. L., Padmanabhan, V., \& Whang, S. (1997). The bullwhip effect in supply chains. Sloan Management Review, (38), 93-102.

Maestrini, V., Luzzini, D., Shani, A. B. R., \& Canterino, F. (2016). The action research cycle reloaded: conducting action research across buyer-supplier relationships. Journal of Purchasing and Supply Management, 22(4), 289-298. http://dx.doi.org/10.1016/j. pursup.2016.06.002.

Micheau, V. A. (2005). How boeing and alcoa implemented a successful vendor managed inventory program. Journal of Business Forecasting, 24(1), 17-19.

Niranjan, T. T., Wagner, S. M., \& Nguyen, S. M. (2012). Prerequisites to vendor-managed inventory. International Journal of Production Research, 50(4), 939-951. http://dx.doi.org/10.1080/00207543.2011.556153.

Oke, A., \& Gopalakrishnan, M. (2009). Managing disruptions in supply chains: a case study of a retail supply chain. International Journal of Production Economics, 118(1), 168-174. http://dx.doi.org/10.1016/j.ijpe.2008.08.045.

Pehanich, M. (2006). MRO strategies mean money in the bank. Food Processing Magazine. Retrieved in 28 October 2006, from http:// www.foodprocessing.com/articles/2005/463.htm

Pohlen, T. L., \& Goldsby, T. J. (2003). VMI and SMl programs: how economic value added can help sell the change. International Journal of Physical Distribution \& Logistics Management, 33(7), 565-581. http://dx.doi.org/10.1108/09600030310499268.

Roy, R., Souchoroukov, P., \& Shehab, E. (2011). Detailed cost estimating in the automotive industry: data and information requirements. International Journal of Production Economics, 133(2), 694-707. http://dx.doi.org/10.1016/j.jpe.2011.05.018.

Rungtusanatham, M., Rabinovich, E., Ashenbaum, B., \& Wallin, C. (2007). Vendor-owned inventory management arrangements in retail: an agency theory perspective. Journal of Business Logistics, 28(1), 111-135. http://dx.doi.org/10.1002/j.2158-1592.2007.tb00234.x.

Schensul, S. L., Schensul, J. J., \& LeCompte, M. D. (1999). Essential ethnographic methods: observations, interviews, and questionnaires (Vol. 2). Walnut Creek: AltaMira Press.

Spradley, J. P. (1980). Participant observation. Belmont: Wadsworth.

Sullivan, L. (2008). Inventory gets back on track. Information Week. Retrieved in 28 October 2006, from http://www.informationweek. com/news/showArticle.jhtml?articlelD=18901689

Tate, W. L., Ellram, L. M., Bals, L., \& Hartmann, E. (2009). Offshore outsourcing of services: an evolutionary perspective. International Journal of Production Economics, 120(2), 512-524. http://dx.doi.org/10.1016/j.jpe.2009.04.005.

Tzeng, S., Chen, W., \& Pai, F. (2008). Evaluating the business value of RFID: evidence from five case studies. International Journal of Production Economics, 112(2), 601-613. http://dx.doi.org/10.1016/j.jpe.2007.05.009.

Valentini, G., \& Zavanella, L. (2003). The consignment stock of inventories: industrial case in performance analysis. International Journal of Production Economics, 81-82, 215-224. http://dx.doi.org/10.1016/S0925-5273(02)00300-6.

Waller, M., Johnson, M. E., \& Davis, T. (1999). Vendor-managed inventory in the retail supply chain. Journal of Business Logistics, 20(1), 183-203.

Wallin, C., Rungtusanatham, M., \& Rabinovich, E. (2006). 'What is the 'right' inventory management approach for a purchased item?'. International Journal of Operations \& Production Management, 26(1), 50-68. http://dx.doi.org/10.1108/01443570610637012.

Wang, S. P., Lee, W., \& Chang, C. Y. (2012). Modeling the consignment inventory for a deteriorating item while the buyer has warehouse capacity constraint. International Journal of Production Economics, 138(2), 284-292. http://dx.doi.org/10.1016/j.ijpe.2012.03.029.

Watson, E. (2005). Nestle switches to vendor managed inventory with Tesco. Food Manufacture, 80(8), 20.

Xu, K., Yin, R., \& Dong, Y. (2016). Stockout recovery under consignment: the role of inventory ownership in supply chains. Decision Sciences, 47(1), 94-124. http://dx.doi.org/10.1111/deci.12198. 
Yin, R. K. (1994). Case study research: design and methods (2nd ed.). Thousand Oaks: Sage Publications.

Yu, Y., Wang, Z., \& Liang, L. (2012). A vendor managed inventory supply chain with deteriorating raw materials and products. International Journal of Production Economics, 136(2), 266-274. http://dx.doi.org/10.1016/j.ijpe.2011.11.029.

Received: Aug. 17, 2017

Accepted: Aug. 21, 2017 